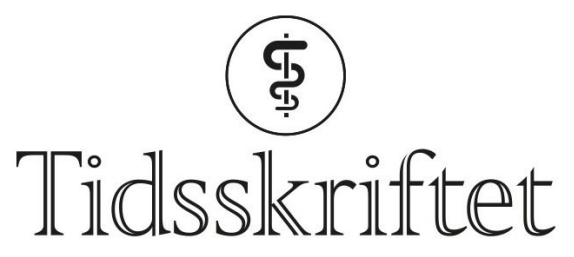

DEN NORSKE LEGEFORENING

\title{
Ikke glem tennene
}

KRONIKK

\section{TORDIS SØRENSEN HØIFØDT}

E-post: tordis.sorensen.hoifodt@unn.no

Tordis Sørensen Høifødt er psykiater ved Psykisk helse- og rusklinikken ved Universitetssykehuset Nord-Norge og førsteamanuensis ved Institutt for klinisk medisin ved Universitetet i Troms $\emptyset$ - Norges arktiske universitet. Hun har bakgrunn fra klinikk, ledelse og forskning, og jobber med forsknings- og forbedringsprosjektet «Bedre psykosebehandling».

Forfatter har fylt ut ICMJE-skjemaet og oppgir ingen interessekonflikter.

\section{ELISABETH LUND-STENVOLD}

Elisabeth Lund-Stenvold er doktorgradsstipendiat ved Institutt for klinisk medisin ved Universitetet i Troms $\emptyset$ - Norges arktiske universitet og lege i spesialisering i psykiatri ved Universitetssykehuset Nord-Norge.

Forfatter har fylt ut ICMJE-skjemaet og oppgir ingen interessekonflikter.

\section{ANNE HØYE}

Anne Høye er psykiater, professorstipendiat ved Institutt for klinisk medisin ved Universitetet i Troms $\emptyset$ - Norges arktiske universitet og overlege ved Psykiatrisk avdeling, Psykisk helse- og rusklinikken, Universitetssykehuset Nord-Norge. Hun har bakgrunn fra klinikk, helseforvaltning og forskning, og er medlem av Tidsskriftets redaksjonskomité.

Forfatter har fylt ut ICMJE-skjemaet og oppgir ingen interessekonflikter.

Pasienter med alvorlig psykisk lidelse har dårligere tannhelse enn befolkningen for øvrig. Med enkle grep kan tannhelsetilbudet for denne gruppen styrkes.

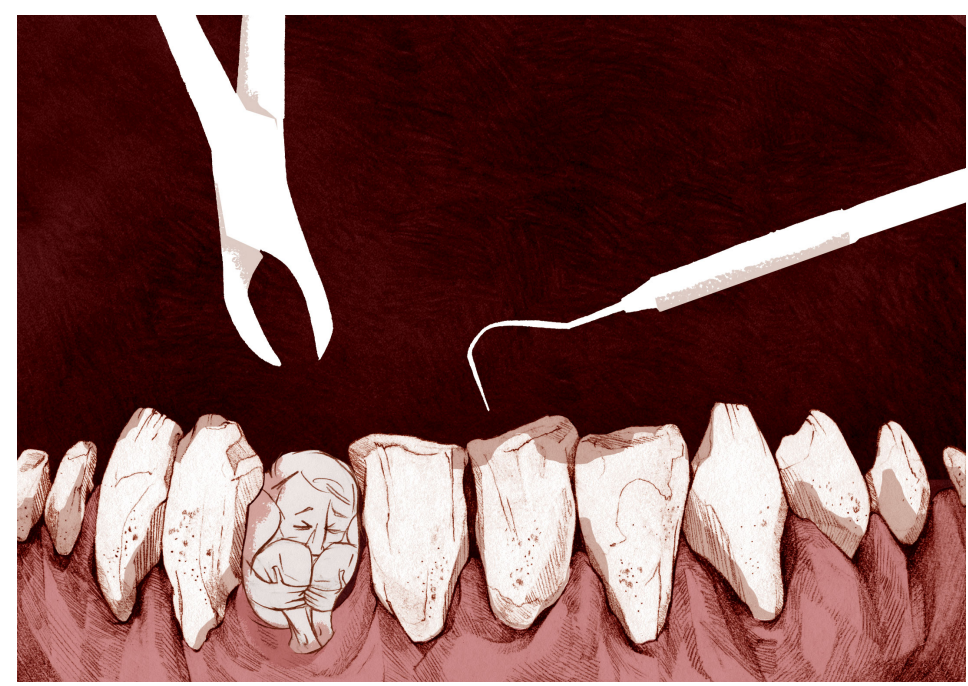

Illustrasjon: Miss Boo/Bente Jørgensen

Den norske befolknings tannhelse er blitt klart bedre de siste 30-40 årene, hovedsakelig på 
grunn av fluorinntak, bedret daglig munnhygiene og $\emptyset \mathrm{kt}$ generell levestandard $(1,2)$. Samtidig er det slik at enkelte grupper fortsatt har større behov for tannhelsetjenester enn resten av befolkningen. Dette inkluderer barn og voksne med funksjonshemning, kreftpasienter og pasienter med alvorlig psykisk lidelse eller rusavhengighet (3). De vanligste tilstandene som affiserer tannhelsen, er karies og periodontitt (2).

\section{Store forskjeller}

Det foreligger få undersøkelser av tannhelse hos alvorlig psykisk syke i Norge, men Haugbo og medarbeidere startet i 2006 et prosjekt ved Lovisenberg Diakonale Sykehus der 26o pasienter med rusavhengighet og psykisk lidelse ble undersøkt og behandlet i løpet av tre år (4). Nesten halvparten av pasientene anga sterk tannbehandlingsfrykt tidlig $\mathrm{i}$ behandlingsforløpet, og ingen hadde gått jevnlig til tannlege. Forekomsten av karies og manglende tenner var høy. Pasienter i aldersgruppen 30-39 år hadde i gjennomsnitt 7,6 tenner med karies. Tilsvarende tall hos friske i aldersgruppen 35-44 år er funnet å være o,8 (5). Pasientene ved Lovisenberg manglet i gjennomsnitt 3,4 tenner, mens tilsvarende hos friske er funnet å være 1,2 $(4,5)$. Det er gjort liknende funn i flere internasjonale studier (6-8). En metaanalyse viste 2,8 ganger økt risiko for tannløshet hos pasienter med alvorlig psykisk lidelse sammenliknet med resten av befolkningen, og signifikant flere manglende tenner og fyllinger (9). En studie fra Danmark viste at kun $43 \%$ av pasienter med schizofreni hadde vært hos tannlegen siste år, mot 68 \% i den danske befolkningen for øvrig (10).

Tannhelse er en viktig del av den fysiske helsen, og dårlig tannhelse er relatert til økt forekomst av hjerte- og karsykdom, diabetes, kreft og luftveissykdommer (11). I tillegg kan dårlig tannstatus påvirke tyggefunksjon og tale og bidra til dårlig selvbilde, som igjen kan begrense sosial fungering. I en kvalitativ undersøkelse fra Sverige fortalte pasienter med alvorlig psykisk lidelse om skam over å ha dårlig tannstatus, belastende erfaring fra tannbehandling og vanskeligheter med å følge opp egen tannhygiene (12).

\section{Mulige årsaker}

Det kan være mange ulike årsaker til problemer med tannhelse, for eksempel dårlig kosthold, røyking, alkohol og rusmiddelbruk. I tillegg kan en rekke psykotrope medikamenter ha bivirkninger relatert til munnhulen, der svekket spyttproduksjon ofte er den mest uttalte (13). Dårlig munnhygiene kan være en viktig tilleggsfaktor; kun $75 \%$ av pasienter med alvorlig psykisk lidelse pusser tennene daglig (6), mot 90-96\% $\mathrm{i}$ normalbefolkningen (14). Tannbehandling er dessuten kostbart, og vi vet at lav sosioøkonomisk status er relatert til dårlig tannhelse, både nasjonalt og globalt $(14,15)$. Dårlig økonomi, manglende betalingsevne og begrenset tilgang til tannhelsetjenester kan derfor være viktige, bidragende årsaker $(10,16)$.

Undersøkelser fra Storbritannia viste at de fleste pasienter som hadde vært i kontakt med psykisk helsevern, aldri var blitt spurt om tannhelse (17). I forskning om tannbehandlingsfrykt er det beskrevet en ond sirkel der angst og frykt medfører unngåelse av tannbehandling med påfølgende dårligere tannhelse, noe som igjen medfører skyld, skam og mindreverdighetsfølelse (18). Undersøkelse av munnhule og tenner er en del av den vanlige medisinske undersøkelsen, men kanskje er det likevel blitt slik det står i en utredning fra Helsedirektoratet (3): «I dag er munnen fysisk, men ikke organisatorisk, en del av kroppen.» Opplever helsepersonell at det er for påtrengende og personlig å spørre om tannhelsen?

\section{Hva kan gjøres?}

Dårlig tannhelse kan forebygges, men det krever målrettede intervensjoner mot risikogrupper. Mye tyder på at tannhelse nedprioriteres når det finnes andre, mer åpenbare symptomer som krever behandling. Vi vet ellers altfor lite om effekten av tiltak, og mer forskning på både individuelle og systemorienterte tiltak er nødvendig (19). En metaanalyse 
fra 2016 om nytte av motivasjon og opplæring i munnhygiene hos psykisk syke gir ingen sikre funn (20). I en av de inkluderte studiene sammenliknet imidlertid Almomani og medarbeidere to randomiserte grupper der begge gruppene fikk opplæring samt en elektrisk tannbørste og påminning om oppfølging av munnhygienen, men der den ene gruppen i tillegg fikk korte økter med motiverende intervju. Begge gruppene fikk redusert mengde plakk, men effekten varte lenger hos de som fikk motiverende intervju (21).

I retningslinjene for utredning, behandling og oppfølging av personer med psykoselidelser anbefales det å legge til rette for rutinemessige tannlegebes $\varnothing \mathrm{k}$. Det understrekes at "[n]år legemidler med antikolinerg effekt brukes, bør pasientene informeres om hvor viktig det er med god tannhygiene» (22). Undersøkelse og behandling av tenner bør også tydeliggjøres som en del av rutinen for innlagte pasienter, særlig for å kunne nå de alvorligst syke (10). Som en enkel kartlegging har tannleger tidligere anbefalt følgende: Tell tennene og henvis videre til tannlege hvis pasienten har færre enn 20 tenner, mangler tenner i front eller har problemer med eller smerter i munnen. En slik kartlegging anbefales av oss, men denne formuleringen finnes ikke lenger i de siste veilederne (14, 23). Som en del av pakkeforløpene for psykisk helse og rus, somatisk helse og levevaner er det foreslått kartleggingsspørsmål som vi også mener er gode (se ramme 1) (24).

\section{Ramme 1 Spørsmål til kartlegging av tannhelse hos pasienter som legges inn i psykisk helsevern eller rusinstitusjoner (24)}

1. Har du smerter eller andre problemer i munnen?

2. Hvor lenge er det siden ditt forrige tannlege-/tannpleierbesøk?

- Hvis det er mer enn to år siden: Hva er årsaken til at du ikke har vært hos tannlege/tannpleier på lang tid?

- Hvis angst er årsaken til at det er over to år siden forrige tannlege-/tannpleierbesøk, skal det opplyses om det i henvisningen til tannlege/tannpleier.

Informer om mulighet for økonomisk stønad til dekning av utgifter til tannbehandling.

\section{Nødvendig med klarere rettigheter}

$\emptyset$ konomiske støtteordninger for tannbehandling er i dag regulert gjennom Lov om tannhelsetjenesten og Lov om folketrygd. Dette innebærer at pasienter som har opphold i institusjon lengre enn tre måneder eller mottar hjemmesykepleie ukentlig over minst tre måneder, har rett til tannlegetjenester vederlagsfritt (25). I tillegg kan pasienter med periodontitt, hyposalivasjon eller sterkt nedsatt evne til egenomsorg være berettiget til å motta økonomisk stønad til nødvendig tannbehandling (26). Pasienter kan også ha rett til $\emptyset$ konomisk stønad til tannbehandling fra NAV (27). Behandlende tannlege er ansvarlig for å innhente nødvendig dokumentasjon. Det er imidlertid slik at selv om det innvilges stønad til tannbehandling, kan pasienten likevel måtte betale høy egenandel på grunn av fri prisfastsettelse i tannhelsetjenesten. Det er derfor svært nærliggende å anta at manglende $\emptyset$ konomi representerer en ytterligere hindring for at pasienter med alvorlig psykisk lidelse får nødvendig oppfølging av tannhelse og tannbehandling, i tillegg til at fortolkning av regelverket kan være komplisert og forutsetter både kunnskap og interesse hos den enkelte behandler og tannlege.

Dårlig tannhelse har vesentlig betydning for alvorlig psykisk syke pasienter, og påvirkningen på selvbilde og livskvalitet må ikke undervurderes. Som helsetjeneste må vi 
derfor sørge for at tannhelsen undersøkes og følges opp på linje med annen somatisk helse. I tillegg må lovverket justeres slik at de formulerte rettighetene tydeliggjøres, og det må klart og tydelig sikres at nødvendig tannbehandling faktisk gis vederlagsfritt til pasienter med alvorlige psykiske lidelser.

LITTERATUR:

1. Holst D, Schuller AA. Oral health changes in an adult Norwegian population: a cohort analytical approach. Community Dent Oral Epidemiol 2000; 28: 102 - 11. [PubMed][CrossRef]

2. St.meld. nr. 35 (2006-2007). Tilgjengelighet, kompetanse og sosial utjevning - Framtidas tannhelsetjenester. https://www.regjeringen.no/no/dokumenter/Stmeld-nr-35-20o6-2007-/id475114/sec1 (29.8.2018).

3. Forsøksordning med orale helsetjenesterorganisert i tverrfaglig miljø i sykehus. IS-2128. Oslo: Helsedirektoratet, 2014 .

https://helsedirektoratet.no/Lists/Publikasjoner/Attachments/99/Forsoksordning-med-orale-helsetjen ester-organisert-i-tverrfaglig-miljo-ved-sykehus-IS-2128.pdf (4.10.2018).

4. Haugbo HO, Storhaug K, Willumsen T. Rusavhengighet, psykiatri og oral helse. Rapport fra et sykehusprosjekt i Oslo. Den norske tannlegeforenings tidende 2010; 120: 912 - 7.

5. Holst D, Schuller AA, Gimmestad A. Tannhelsen i dynamisk endring - fra sykdomsrisiko til helsepotensial. Den norske tannlegeforenings tidende 2004; 114: 866 - 71.

6. McCreadie RG, Stevens H, Henderson J et al. The dental health of people with schizophrenia. Acta Psychiatr Scand 2004; 110:306 - 10. [PubMed][CrossRef]

7. Wey MC, Loh S, Doss JG et al. The oral health of people with chronic schizophrenia: A neglected public health burden. Aust N Z J Psychiatry 2016; 50: 685 - 94. [PubMed][CrossRef]

8. Matevosyan NR. Oral health of adults with serious mental illnesses: a review. Community Ment Health J 2010; 46: 553 - 62. [PubMed][CrossRef]

9. Kisely S, Baghaie H, Lalloo R et al. A systematic review and meta-analysis of the association between poor oral health and severe mental illness. Psychosom Med 2015; 77: 83 - 92. [PubMed][CrossRef]

10. Nielsen J, Munk-Jørgensen P, Skadhede S et al. Determinants of poor dental care in patients with schizophrenia: a historical, prospective database study. J Clin Psychiatry 2011; 72: 140 - 3.

[PubMed][CrossRef]

11. Chapple IL. The impact of oral disease upon systemic health-Symposium overview. J Dent 2009; 37: S568 - 71. [PubMed][CrossRef]

12. Persson K, Olin E, Ostman M. Oral health problems and support as experienced by people with severe mental illness living in community-based subsidised housing-a qualitative study. Health Soc Care Community 2010; 18: 529-36. [PubMed][CrossRef]

13. Cockburn N, Pradhan A, Taing MW et al. Oral health impacts of medications used to treat mental illness. J Affect Disord 2017; 223: 184 - 93. [PubMed][CrossRef]

14. Tenner for livet. Helsefremmende forebyggende arbeid. IK-2659. Oslo: Statens helsetilsyn, 1999. https://helsedirektoratet.no/Lists/Publikasjoner/Attachments/484/Tenner-for-livet-helsefremmende-o g-forebyggende-arbeid-IS-2659.pdf(29.8.2018).

15. Petersen PE, Kwan S. Equity, social determinants and public health programmes-the case of oral health. Community Dent Oral Epidemiol 2011;39:481 - 7. [PubMed][CrossRef]

16. Kisely S. No mental health without oral health. Can J Psychiatry 2016; 61: 277 - 82.

[PubMed][CrossRef]

17. Kisely S, Quek LH, Pais J et al. Advanced dental disease in people with severe mental illness: systematic review and meta-analysis. Br J Psychiatry 2011; 199: 187 - 93. [PubMed][CrossRef]

18. Berggren U, Meynert G. Dental fear and avoidance: causes, symptoms, and consequences. J Am Dent Assoc 1984; 109: 247 - 51. [PubMed][CrossRef]

19. Palmier-Claus JE, Shiers D, French P et al. Oral health in psychosis: An unmet need. Schizophr Res 
20. Khokhar MA, Khokhar WA, Clifton AV et al. Oral health education (advice and training) for people with serious mental illness. Cochrane Database Syst Rev 2016; 9: CDoo88o2. [PubMed]

21. Almomani F, Williams K, Catley D et al. Effects of an oral health promotion program in people with mental illness. J Dent Res 2009; 88: 648 - 52. [PubMed][CrossRef]

22. Utredning, behandling og oppfølging av personer med psykoselidelser. IS-1957. Oslo:

Helsedirektoratet, 2013 .

https://helsedirektoratet.no/Lists/Publikasjoner/Attachments/326/Nasjonal-faglig-retningslinje-for-utr edning-behandling-og-oppfolging-av-personer-med-psykoselidelser-IS-1957.pdf (29.8.2018).

23. God klinisk praksis i tannhelsetjenesten - en veileder i bruk av faglig skjønn ved nødvendig tannbehandling. Oslo: Helsedirektoratet, 2011.

https://helsedirektoratet.no/Lists/Publikasjoner/Attachments/485/God-klinisk-praksis-i-tannhelsetjen esten-en-veileder-i-bruk-av-faglig-skjonn-ved-nodvendig-tannbehandling-IS-1589.pdf(29.8.2018).

24. Tannhelse - pakkeforløp for psykisk helse og rus. Helsedirektoratet.

https://helsedirektoratet.no/retningslinjer/somatisk-helse-og-levevaner-pakkeforlop-for-psykisk-helse -og-rus/seksjon?Titteltannhelse-pakkeforlop-for-11423\#oppfølging-av-tannhelse-hos-pasienter-medpsykiske-lidelser-og/eller-rusmiddelproblemer (4.10.2018).

25. LOV-1983-o6-03-54. Lov om tannhelsetjenesten (tannhelsetjenesteloven). https://lovdata.no/dokument/NL/lov/1983-o6-03-54(29.8.2018).

26. Rundskriv I-8/2017 Regelverk og takster vedrørende stønad til dekning av utgifter til tannbehandling for 2018 - revidert 16. februar 2018.

https://www.regjeringen.no/no/dokumenter/rundskriv-i-72017-regelverk-og-takster-vedrorende-stona d-til-dekning-av-utgifter-til-tannbehandling-for-2018/id2582852/(29.8.2018).

27. Rundskriv Hovednr. 35 - Sosialtjenesteloven. Oslo: Arbeids- og velferdsdirektoratet, 2012. https://www.nav.no/rettskildene/Rundskriv/hovednr.35-lov-om-sosiale-tjenester-i-nav (29.8.2018).

Publisert: 27. november 2018. Tidsskr Nor Legeforen. DOI: 10.4045/tidsskr.18.0581 Mottatt 19.7.2018, første revisjon innsendt 7.9.2018, godkjent 4.10.2018.

(C) Tidsskrift for Den norske legeforening 2020. Lastet ned fra tidsskriftet.no 